\title{
Leitlinie zum IK
}

\section{SIMPLY CLEVER SINGLE HAND USE}

\section{Evidenz bei neurologischen Störungen}

Bei neurogenen Blasenfunktionsstörungen stellt der intermittierende Katheterismus (IK) seit den 1960er Jahren die Methode der Wahl zur Blasenentleerung dar. Im vergangenen Jahr legte die Deutsche Gesellschaft für Urologie ein S2k-Leitlinie vor, um Management und Durchführung des IK bei neurogenen Blasenfunktionsstörungen auf der Grundlage der verfügbaren Evidenz zur Verfügung zu stellen.

Der aseptische Katheterismus stellt auch in der Langzeitanwendung eine komplikationsarme Methode zur druck- und restharnfreien Entleerung der Harnblase für Patienten mit neurogenen Blasenfunktionsstörungen dar. Da die bisherigen Empfehlungen auf Erfahrungswerten basieren, soll der nun vorliegende Konsensus dazu beitragen, die Handhabung des IK zu vereinheiten, Verunsicherungen zu beseitigen und den Anwendern eine Hilfestellung zu bieten.

Für die Daueranwendung werden als besondere Merkmale der Katheter eine atraumatische Spitze, abgerundete Katheteraugen ohne scharfe Kanten und eine Oberfläche, die zusammen mit den speziellen Gleitsubstanzen ein Optimum an Gleitfähigkeit besitzt, angeführt.

Quelle: I. Kurze et al.: S2k-Leitlinie der Deutschen Gesellschaft für Urologie, in: Urologe 2015, 54:385-393; DOI 10.1007/s00120-014-3701-3

\section{Cathejell - \\ Simply Clever aus Österreich}

Cathejell ist ein steriles, desinfizierendes, wasserlösliches und sichtklares Gleitgel, das die Katheterisierung oder das Einführen von medizinischen Instrumenten in die Harnröhre sanft und schmerzfrei ermöglicht.

Das Gel ist in Österreich als Arzneimittel und als Medizinprodukt verfügbar.

Die Instillation eines Gleitgels bedingt die sanfte Entfaltung der Harnröhre. Die Urethra wird gleichmäßig mit einem Gleitfilm bedeckt.

- erleichtert Eingriffe

- schützt vor Verletzungen

- reduziert das Infektionsrisiko

- lindert Schmerzen

Cathejell Produkte sind hervorragend geeignet für den Einsatz:

- im sterilen OP Bereich

- in der ärztlichen Praxis

- in der häuslichen Umgebung

Die Zieharmonikaspritze ermöglicht die langsame, dosierbare Instillation mit einer Hand.

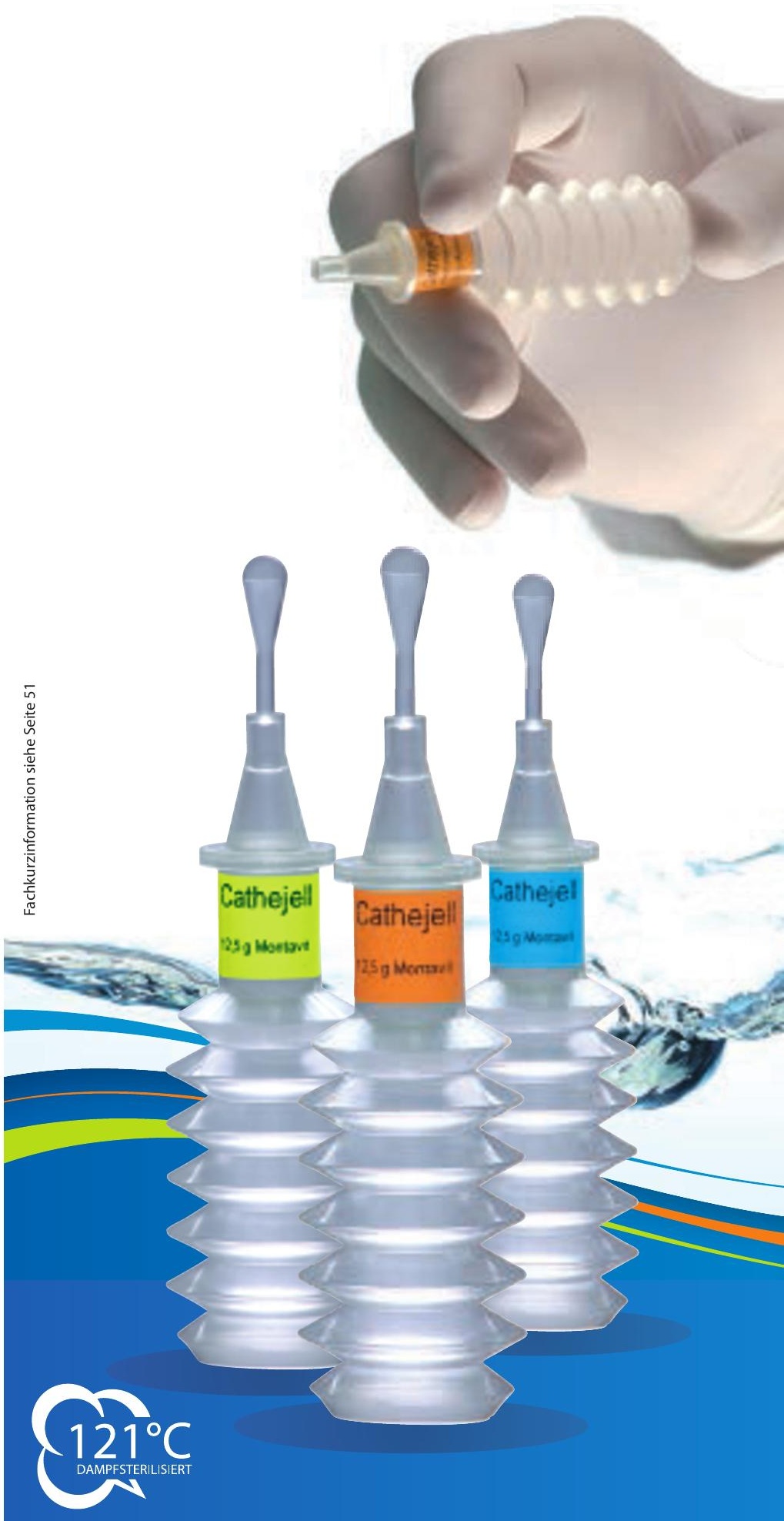

DAS STERILE KATHETERGLEITGEL

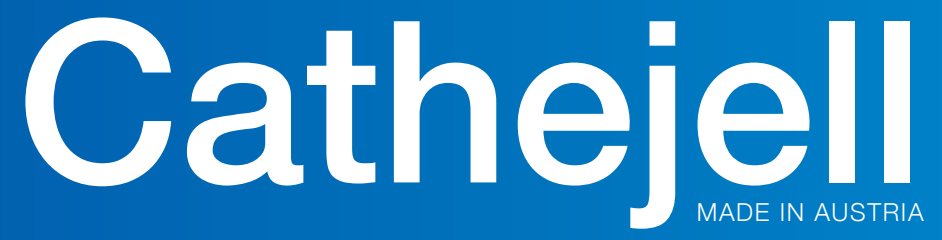

Mehr zu SIMPLY CLEVER Cathejell erfahren Sie auf www.montavit.com 